\title{
Perspectives
}

\section{Perspectives of Heat Stroke Shield: An IoT based Solution for the Detection and Preliminary Treatment of Heat Stroke}

\author{
Sadia Javed \\ Department of Computer Science and \\ Software Engineering \\ Jinnah University for Women \\ Karachi, Pakistan \\ sadi0921@gmail.com
}

\author{
Samia Ghazala \\ Department of Computer Science and \\ Software Engineering \\ Jinnah University for Women \\ Karachi, Pakistan \\ samia_ghazala@yahoo.com
}

\author{
Ummay Faseeha \\ Department of Computer Science and \\ Software Engineering \\ Jinnah University for Women \\ Karachi, Pakistan \\ uf_uit@yahoo.com
}

\begin{abstract}
Heat stroke is considered a major problem in Karachi, with a considerable number of people recorded as victims each year. The proposed Internet-of-Things (IoT) based heat stroke shield works under heat stroke conditions, depending on a heat index value (atmospheric temperature and humidity). The system comprises of a wristband, a hardware kit and an alert system which can pre-notify a wearer regarding his body parameter readings. Moreover, the system can also work as a problem solver, in heat stroke condition, by showering water on the victim. In both cases, an alert will also be generated to the wearer's caretakers with his GPS location.
\end{abstract}

Keywords-Internet-of-Things; gsm module; heat stroke; wearable

\section{INTRODUCTION}

Global warming consists of a constant and continuous rise in the temperature of earth's atmosphere [1]. Among its many catastrophic impacts, this rise in temperature has been an evident cause of heat waves [2]. Continuous temperatures above $32^{\circ} \mathrm{C}$ for three days is an obvious condition of heat wave [3]. It is a prevalent natural climatic hazard with perceptible impacts on the humans and biophysical systems and is considered to be a global and constantly growing problem. Heat wave cycle repeats on a yearly basis normally in summer season with symptoms such as heat stress, heat exhaustion and heat stroke. People who work in the sun continuously suffer from sun stroke because of the excessive heat accumulated in their body due to the continuous exposure. Also, elders, specifically those with circulatory diseases are most vulnerable to heat stroke [4]. Children are also considered to be a high risk group to face heat exhaustion and heat stroke related problems. Pakistan has been a victim of heat waves [5]. The heat waves are common in pre-monsoon months (April-June) in the plains of the country. In June 2015, the southern part of Pakistan was affected by a severe heat wave in which temperature raised above $45^{\circ} \mathrm{C}$. Reported mortalities were due to suffocation, dehydration and heat strokes [6]. The death toll for this year rose noticeably to about 1200 individuals, resulting in a stateof-emergency being declared at all public hospitals and morgues. From 2015 onwards, people face extreme weather conditions each year and a noticeable number of individuals get affected. Densely populated cities are more vulnerable to negative impacts of heat waves in Pakistan [7, 8]. Karachi is one of the most heat stroke affected cities of Pakistan. The sea breeze moderates the city's climate as it is located on the coast of the Arabian Sea. Due to the sea breeze a low-pressure system generates in the ocean which may lead to a spike in temperature. It causes the body temperature to increase and affects the nervous system rapidly [9] resulting in death or permanent organ damage or disability if not properly treated on time. Furthermore, global climate change makes summers even hotter. This weather fluctuation impact gets worse due to the insufficient functioning of the weather forecast system [10].

To deal with the heat stroke problem, an IoT based prototype is discussed in this paper which is using sensors to measure certain parameters like body temperature, oxygen level, and heat index (atmospheric temperature and humidity). Wearing the proposed wristband, heat stroke can be detected in advance, on the basis of these parameters, in children, elderly, and adults. A hardware kit, specifically for bedridden or on a wheel chair patients, is also integrated with the wristband for sprinkling water vapors on the heat stroke victim.

\section{RELATED WORK}

New technological advancements in the field of communications, specifically in mobile network and sensor technology, are further improving the channels and removing the existing obstacles [11]. A new technological era of Internet of Things (IoT) is emerging rapidly and many vendors are constructing sensor enabled devices which follow the open standards allowing these devices to be integrated with any type of system, i.e. inventory management systems, customer 
support systems, business intelligence, and health care applications [12]. Data acquisition, analysis and processing have become more convenient and transparent with the support of IoT. Health services are also actively taking part by providing information on time [13]. In IoT based healthcare systems, a patient/victim can not only be monitored remotely but an automated cure can be provided as first aid in case of an emergency. A model which is efficiently dealing with real time data for the health care system by taking advantage of IoT is proposed in [14]. Similarly, a number of wearable physiological monitoring systems has been developed focusing mainly on the heat illness of astronauts, athletes, firefighters, and soldiers. These systems comprise of an array of sensors that can be assimilated with clothes/wearables to continuously sense the physical parameters of the wearer and keep track of his/her health status effectively [15]. Similar systems have been proposed for treating heat exhaustion or heat stroke. In [16], heat stress monitoring is done by a flexible Bluetooth based self-adhesive patch which is attached on the chest of the patient. It analyzes heat illness by monitoring certain body parameters. A heat illness monitoring system for firefighters is proposed in [17], which uses a wearable shirt integrated with sensors to analyze temperature, humidity, and heart rate. The low energy wireless protocol Zigbee is used for sending the information to the remote device. Another Zigbee based wearable device is proposed in [18] which is worn on the wrist and the finger of a person (athlete or infant). It is used to check heart rate and temperature of the wearer and an alert message is sent to the caretakers if the parameters reach a certain threshold. Temperature and heart rate sensors fabricated on gloves are used to detect heat stroke conditions. A smart watch uses body temperature for the prediction of heat stroke in [19] with water intake also monitored by the system. A GPRS and WiFi based system is discussed in [20] which is mainly focusing on the detection of the presence of humans, especially children, inside locked cars. Heat stroke is monitored by temperature sensor and an alert is generated to the owner of the car in case of emergency. Likewise, a Bluetooth/GPRS based system is proposed to address heat stroke in [21], in which an accelerometer sensor is used to detect user movement. The movement detection beyond a certain defined threshold will result in alarm generation. Nontechnical solutions to control body temperature in case of heat exertion are discussed in [22]. Body temperature can be dropped by $0.35^{\circ} \mathrm{C} / \mathrm{min}$ if the patient is immersed in cold water at $2^{\circ} \mathrm{C}$ while the temperature decreasing rate in an air-conditioned rooms is only around $0.05^{\circ} \mathrm{C}$. Alternatively, applying ice packs or crushed ice can also be used to lower body temperature up to a certain limit $[23,24]$. These methods can work efficiently with excertional heat strokes. In the case of non-exertional heat strokes, air blow with water spray can bring gradual change in the body temperature up to $0.31^{\circ} \mathrm{C} / \mathrm{min}[25]$.

TABLE I. COMPARISON OF DIFFERENT HEAT STRESS MONITORING SYSTEMS

\begin{tabular}{|c|c|c|c|c|c|}
\hline Heat stress monitoring system & $\begin{array}{c}\text { Communication } \\
\text { technology }\end{array}$ & Hardware & Body parameters analyzed & Target audience & $\begin{array}{c}\text { System } \\
\text { alert }\end{array}$ \\
\hline $\begin{array}{l}\text { Flexible self-adhesive patch type system for } \\
\text { professional heat stress monitoring [16] }\end{array}$ & Bluetooth & Self-adhesive patch & $\begin{array}{c}\text { ECG, body temperature, } \\
\text { humidity, 2-axis acceleration }\end{array}$ & $\begin{array}{l}\text { Heat stress victim } \\
\text { of any age group }\end{array}$ & No \\
\hline $\begin{array}{l}\text { Wearable system for heat stress monitoring in } \\
\text { firefighting applications [17] }\end{array}$ & Zigbee & Wearable shirt & $\begin{array}{l}\text { Temperature, humidity, } \\
\text { heart rate, }\end{array}$ & Firefighters & No \\
\hline $\begin{array}{l}\text { A Zigbee-based wearable physiological } \\
\text { parameters monitoring system [18] }\end{array}$ & Zigbee & Wristband, finger clip & Heart rate, temperature & Athlete or infant & Yes \\
\hline Heat stroke detection system based in IoT [15] & TCP/IP & Hang Glove & Heart rate, temperature & $\begin{array}{c}\text { Children, elderly } \\
\text { people, adults of } \\
\text { productive age }\end{array}$ & Yes \\
\hline HeatWatch [19] & Bluetooth & Smart watch, smartphone & $\begin{array}{c}\text { Body temperature, water } \\
\text { intake }\end{array}$ & All age groups & No \\
\hline $\begin{array}{l}\text { Affordable system for alerting, monitoring and } \\
\text { controlling heat stroke inside vehicles [20] }\end{array}$ & GPRS/WiFi & Smart vehicle & $\begin{array}{c}\text { Temperature sensor, } \\
\text { presence detection, location }\end{array}$ & Children & Yes \\
\hline $\begin{array}{l}\text { Minimizing heatstroke incidents for young } \\
\text { children left inside vehicles [21] }\end{array}$ & Bluetooth/ GPRS & Estimate Beacon device & Movement detection & Children & Yes \\
\hline
\end{tabular}

\section{PROPOSED SYSTEM DESIGN}

\section{A. Controling Element}

The Arduino Nano comprises of an ATmega328P microcontroller bearing the same features as Arduino Uno with compact size and 8 analog ports (A0-A7) and 11 general purpose digital ports (D2-D12). The small size and advanced features of Arduino prove it to be an appropriate choice for wearable devices [26-31]. Arduino IDE platform is used to program the controller as per the desired features of the proposed system. It processes the information received from the sensors and sends the information through the wireless medium to the android application used by the caretaker and the designed kit simultaneously, in case of emergency for treatment from the adverse effects of heat waves. The proposed system works on an IoT concept to provide connectivity between the wearable device and the mobile application without human intervention.

\section{B. Sensors for Parameters' Intuiting}

A heat stroke can be harmful if the patient is not treated urgently due to the rise in body temperature (greater than $40.0^{\circ} \mathrm{C}$ ). Therefore, in this proposed system, real time data of the following parameters will be sensed by respective sensors:

- Body temperature

- Blood oxygen level

- Heat index (comprised of environmental temperature and humidity)

A body temperature sensor is connected with the analog input pin, a heat index sensor with a digital input pin and a 
blood oxygen sensor with another analog input pin of the Arduino to analyze and compare received data with the saved information. All the sensors are embedded in the wearable device.

\section{1) Human Body Temperature Sensor}

Humans are effected by heat stroke majorly due to the change in body temperature with respect to change in environmental temperature and humidity level. Environmental temperature and humidity level are collectively called heat index [32]. Therefore, the proposed system is focused on human body temperature in comparison with external weather conditions. MLX90614 sensor is a non-contact infrared thermometer connected at a digital input of the Arduino embed in the wrist band and measures the infrared radiation emitted from the human body. The purpose of the controller is to absorb infrared radiation from the body and convert it to heat. The heat is converted into electrical energy, which is communicated to a detector to determine the temperature of the body. The normal range of human body temperature is between $37-38^{\circ} \mathrm{C}$, when heat index reading is between $27-32^{\circ} \mathrm{C}$. Therefore, the effected person or the caretaker must be cautious and have to take some measures to drop body temperature. However, if the temperature of the human body raises from 39$40^{\circ} \mathrm{C}$ at heat indexbetween $32-41{ }^{\circ} \mathrm{C}$, then the person needs extreme attention because these symptoms of heatstroke can be lethal and the patient's body temperature must drop quickly. In the proposed solution, MLX90614 sensor is used for the continuous monitoring of the human body temperature along with the other parameters such as heat index and oxygen level.

TABLE II. HEAT STOKE AND ENVIRONMENTAL PARAMETER EFFECTS

\begin{tabular}{|c|c|c|c|}
\hline $\begin{array}{c}\text { Heat index } \\
\left({ }^{\circ} \mathbf{C}\right)\end{array}$ & $\begin{array}{c}\text { Body } \\
\text { temperature }\left({ }^{\circ} \mathbf{C}\right)\end{array}$ & $\begin{array}{c}\text { Oxygen level } \\
(\mathbf{m m ~ H g})\end{array}$ & Observation \\
\hline $27-32$ & $37-38$ & $75-73$ & Caution \\
\hline $32-41$ & $39-40$ & $72-70$ & Extreme caution \\
\hline $41-54$ & $41-42$ & $69-65$ & Danger \\
\hline Over 54 & Above 42 & Less than 65 & Extreme danger \\
\hline
\end{tabular}

\section{2) Heat Index}

Heat index is used to measure apparent temperature or feellike temperature. Therefore, the proposed system focuses on environmental temperature and humidity along with other parameters. An SHT75 sensor is used to sense environment temperature and humidity levels. It consists of a capacitive element which measures relative humidity and a band gap sensor which measures temperature. The sensor is connected with an analog pin of the controller and gives the results in digital form. Ther output of SHT75 will be compared with the output of the MLX90614 sensor and SpO2 sensor to get the actual impact of heat wave on human body.

\section{3) Light-based $\mathrm{SpO} 2$ sensor}

In the proposed idea, $\mathrm{SpO} 2$ is used to sense the oxygen level of the human body, it is a clamp-like device which is connected to the input of the Arduino in a wrist band. Minorrays of light pass through the blood in the wrist, measuring the amount of oxygen through the changes of light absorption in oxygenated or deoxygenated blood.

\section{Communication Technology}

Long range wireless connectivity is required for the uninterupted flow of sensed data in the case of an emergency. Therefore, a GSM/GPRS module is used for sending alert messages to the registered number of the caretaker. The GSM module is heplful to mentain long range wireless communication between the caretake and the wearer. It is the most suitable device for IoT applications because of its size and features of text messaging, phone calling, and accessing the internet through GPRS. However, GPRS services will not be used to avoid the additional penetration of harmful rays in human body.

\section{IMPLEMENTATION}

The methodology of the proposed system is shown in Figure 1 in which environmental parameters (heat index) along with human body temperature and oxygen level are the main areas of concern in case of extreme weather conditions. Therefore, the decision of sending alert or activation of the showering kit will be depending upon the parameters discussed in Table I. The proposed system will be composed of two modules. The first module is based on a wearable wristband which is used while the user is in mobility as shown in Figure 2. Figure 3 shows the second module comprised of a wristband along with a showering kit for immobilized persons.

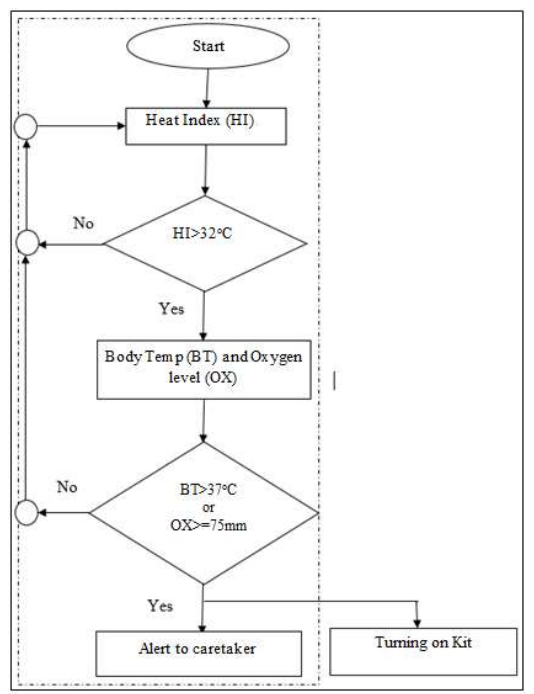

Fig. 1. Data flow of the proposed system

The wristband in both modules is designed with embedded sensors. MLX90614, SpO2 and SHT75 sensors are used to monitor heat index, body temperature, and oxygen level respectively. The working of the wristband will start with the sensing of the value of heat index (HI). If the $\mathrm{HI}$ value is greater than $32^{\circ} \mathrm{C}$, it is considered an indication of extreme caution for heat stroke. To examine accurately, the processing unit will immediately check body temperature and oxygen level. If the body temperature increases to $39^{\circ} \mathrm{C}$ or above and the oxygen level decrease below $70 \mathrm{~mm} \mathrm{Hg}$, then it is 
considered a certain condition of heat stroke and the GSM module placed on the wristband will send an alert message to the caretaker. If the wearer also wants to keep track of his fluctuating condition, he can also get alert on his mobile device and can take precautionary measures himself. This is considered to be an obvious advantage of this setup.

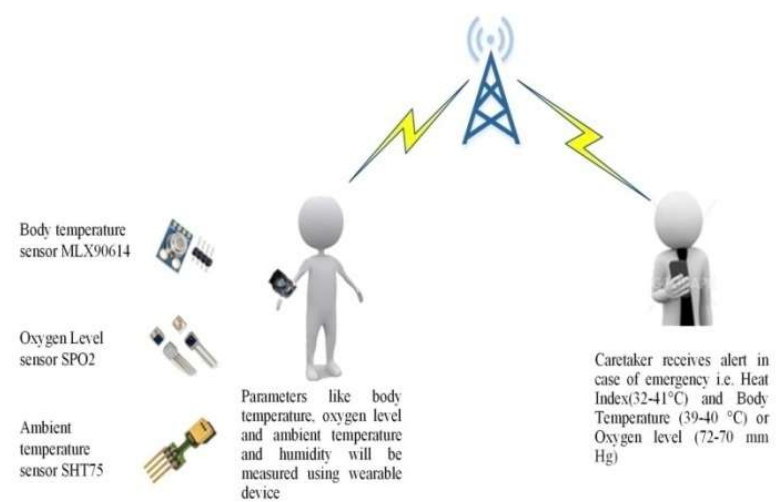

Fig. 2. Proposed system module 1: wearable wrist band

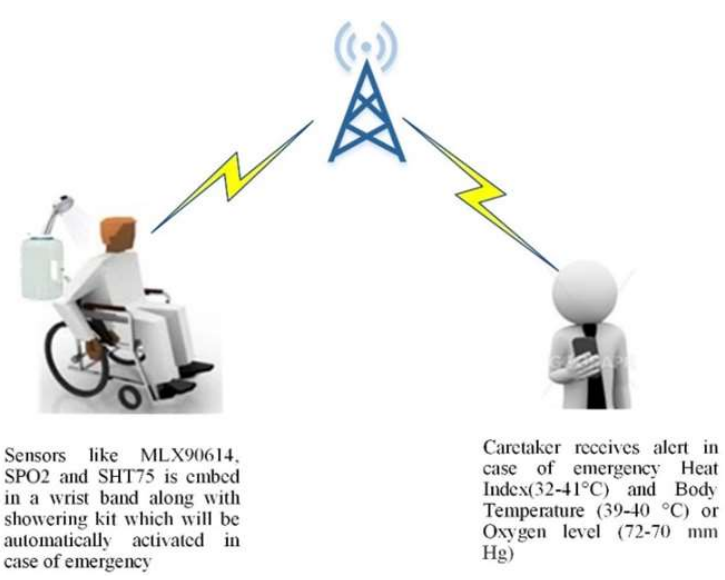

Fig. 3. Proposed system module 2: wristband along with showering kit

The same setup followed by a water showering kit will be used as a second module. This device will be designed especially for patients. In addition to generate an alert from wristband to the caretaker, a Bluetooth enabled showering kit will also start working on the same values of monitored parameters. Kit will shower water vapors on the heat stroke victim progressively until the caretaker handles the condition of the patient. This will act like first aids for the patient when no one is nearby to take care of him in a case of an emergency. The second module is covering both features of the system, i.e. monitoring and treating.

\section{TEST CASE}

A solution is proposed for addressing heat stroke by measuring body temperature and oxygen level of an elder adult. Figure 4 shows the prototype of the system. A site in Karachi has been selected for experiment in the extreme weather of June, 2019. The observed heat index and body temperature were $43.2^{\circ} \mathrm{C}$ and $39.2^{\circ} \mathrm{C}$ respectively. The system successfully generated an alert message to caretaker's contact number fed already in the application.

\section{CONCLUSION AND FUTURE WORK}

The proposed system is an attempt to address cataclysmic situations of heat stroke. The wristband contains sensors for continous measurement of crucial parameters like body temperature, oxygen level, and heat index, and it can also send alert messages to the caretakers in a case of an emergency. This is beneficial for all age groups and for persons engaged in different outdoor activities. The integrating hardware kit with wristband, especifically working for debridden patients and elderly people, is used to provide first aid as well. Architecture and simple design corroborate to make it an afforable and easily implementable system. In the future, more parameters like pulse rate and sweating can be monitored considering other illnesses or diseases.

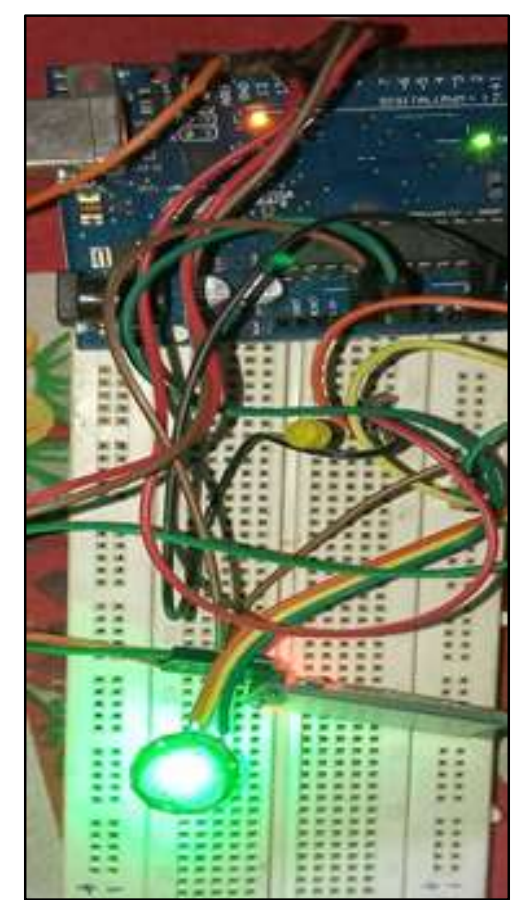

Fig. 4. The prototype of the proposed system

\section{REFERENCES}

[1] T. P. Hughes, J. T. Kerry, S. K. Wilson, "Global warming and recurrent mass bleaching of corals", Nature, Vol. 543, pp. 373-377, 2017

[2] M. S. Nashwan, S. Shahid, "Spatial distribution of unidirectional trends in climate and weather extremes in Nile river basin", Theoretical and Applied Climatology, Vol. 137, pp. 1181-1199, 2019

[3] M. Akbar Baig, S. Waheed, A. Mian, E. Hussain, "Unforgiving heat wave deaths in the largest metropolitan city of Pakistan: Lessons learned", Eurasian Journal of Emergency Medicine, Vol. 14, pp. 209210,2015

[4] S. Rauf, K. Bakhsh, A. Abbas, S. Hassan, A. Ali, H. Kachele, "How hard they hit? Perception, adaptation and public health implications of heat waves in urban and peri-urban Pakistan", Environmental Science and Pollution Research, Vol. 24, pp. 10630-10639, 2017

[5] N. Khan, S. Shahid, T. Ismail, K. Ahmed, N. Nawaz, "Trends in heat wave related indices in Pakistan", Stochastic Environmental Research and Risk Assessment, Vol. 33, pp. 287-302, 2019 
[6] S. G. Saleem, T. Ansari, A. S. Ali, S. Fatima, M. H. Rizvi, M. A. Samad, "Risk factors for heat related deaths during the June 2015 heat wave in Karachi, Pakistan", Journal of Ayub Medical College Abbottabad, Vol. 29, No. 2, pp. 320-324, 2017

[7] A. Mhatre, V. Thengre, H. Sharma, S. Sharma, "Design of smart cooling jacket for 2-wheeler riders", International Journal of Recent Trends in Engineering and Research, Vol. 4, No. 3, pp. 211-216, 2018

[8] S. Ullah, Q. You, A. Ali, W. Ullah, M. A. Jan, Y. Zhang, W. Xie, X $\mathrm{Xie}$, "Observed changes in maximum and minimum temperatures over China-Pakistan economic corridor during 1980-2016", Atmospheric Research, Vol. 216, pp. 37-51, 2019

[9] S. Percic, A. Kukec, T. Cegnar, A. Hojs, "Number of heat wave deaths by diagnosis, sex, age groups, and area, in Slovenia, 2015 vs. 2003", International Journal of Environmental Research and Public Health, Vol. 15, No. 1, Article ID 173, 2018

[10] K. Ahmed, S. Shahid, N. Nawaz, N. Khan, "Modeling climate change impacts on precipitation in arid regions of Pakistan: A non-local model output statistics downscaling approach", Theoretical and Applied Climatology, Vol. 137, pp. 1347-1364, 2019

[11] T. Lang, "Advancing global health research through digital technology and sharing data", Science, Vol. 331, pp. 714-717, 2011

[12] I. Lee, K. Lee, "The Internet of Things (IoT): Applications, investments, and challenges for enterprises", Business Horizons, Vol. 58, No. 4, pp. 431-440, 2015

[13] A. Geissbuhler, "Access to health information: a key for better health in the knowledge society", Yearbook of Medical Information, Vol. 17, No. 1, pp. 20-21, 2008

[14] J. Luo, K. Tang, Y. Chen, J. Luo, "Remote monitoring information system and its applications based on the Internet of Things", International Conference on Future BioMedical Information Engineering, Sanya, China, December 13-14, 2009

[15] M. Haghi, K. Thurow, R. Stoll, "Wearable devices in medical Internet of Things: Scientific research and commercially available devices", Healthcare Informatics Research, Vol. 23, No. 1, pp. 4-15, 2017

[16] D. G. Park, S. C. Shin, S. W. Kang, Y. T. Kim, "Development of flexible self adhesive patch for professional heat stress monitoring service", IEEE Engineering in Medicine and Biology 27th Annual Conference, Shanghai, China, January 17-18, 2005

[17] G. Florea, R. Dobrescu, D. Popescu, M. Dobrescu, "Wearable system for heat stress monitoring in firefighting applications", Recent Advances in Computer Science and Networking, pp. 129-134, 2013

[18] K. Malhi, S. C. Mukhopadhyay, J. Schnepper, M. Haefke, H. Ewald, "A Zigbee-based wearable physiological parameters monitoring system”, IEEE Sensors Journal, Vol. 12, No. 3, pp. 423-430, 2012

[19] T. Hamatani, A. Uchiyama, T. Higashino, "HeatWatch: Preventing heatstroke using a smart watch", IEEE International Conference on Pervasive Computing and Communications Workshops (PerCom Workshops), Kona, USA, March 13-17, 2017

[20] S. Garethiya, H. Agrawal, S. Gite, Suresh, V. A. Kudale, G. Wable, G. R. Yendargaye, "Affordable system for alerting, monitoring and controlling heat stroke inside vehicles", International Conference on Industrial Instrumentation and Control, Pune, India, May 28-30, 2015

[21] H. Mahdin, A. H. Omar, S. S. Yaacob, S. Kasim, M. F. M. Fudzee, "Minimizing heatstroke incidents for young children left inside vehicle", IOP Conference Series: Materials Science and Engineering, Vol. 160, Article ID 012094, 2016

[22] F. G. Gaudio, C. K. Grissom, "Cooling methods in heat stroke", The Journal of Emergency Medicine, Vol. 50, No. 4, pp. 607-616, 2016

[23] A. Bouchama, M. Dehbi, E. C. Carballo, "Cooling and hemodynamic management in heatstroke: Practical recommendations", Critical Care, Vol. 11, Article ID R54, 2007

[24] J. E. Smith, "Cooling methods used in the treatment of exertional heat illness", British Journal of Sports Medicine, Vol. 39, No. 8, pp. 503-507, 2005

[25] A. J. Kielblock, J. P. V. Rensburg, R. M. Franz, "Body cooling as a method for reducing hyperthermia. An evaluation of techniques", South African Medical Journal, Vol. 69, No. 6, pp. 378-380, 1986

[26] K. Krishnamurthi, S. Thapa, L. Kothari, A. Prakash, "Arduino based weather monitoring system", International Journal of Engineering Research and General Science, Vol. 3, No. 2, pp. 452-458, 2015

[27] A. D. Deshmukh, U. B. Shinde, "A low cost environment monitoring system using Raspberry $\mathrm{Pi}$ and Arduino with Zigbee", International
Conference on Inventive Computation Technologies, Coimbatore, India, August 26-27, 2016

[28] S. Lee, J. Jo, Y. Kim, H. Stephen, "A framework for environmental monitoring with Arduino-based sensors using restful web service", IEEE International Conference on Services Computing, Anchorage, USA, June 27-July 2, 2014

[29] S. Ferdoush, X. Li, "Wireless sensor network system design using Raspberry Pi and Arduino for environmental monitoring applications", Procedia Computer Science, Vol. 34, pp. 103-110, 2014

[30] V. Tiwari, A. Keskar, N. C. Shivaprakash, "Design of an IoT enabled local network based home monitoring system with a priority scheme", Engineering, Technology \& Applied Science Research, Vol. 7, No. 2, pp. 1464-1472, 2016

[31] S. Zafar, G. Miraj, R. Baloch, D. Murtaza, K. Arshad, “An IoT based real-time environmental monitoring system using Arduino and cloud service", Engineering, Technology \& Applied Science Research, Vol. 8, No. 4, pp. 3238-3242, 2018

[32] P. O. Antonio, C. M. Rocio, R. Vicente, B. Carolina, B. Boris, "Heat stroke detection system based in IoT", IEEE Second Ecuador Technical Chapters Meeting, Salinas, Ecuador, October 16-20, 2018 